The Role of Culture in Explaining College Student's Selection into Hookups, Dates, and Long-Term Romantic Relationships

By: Arielle Kuperberg and Joseph E. Padgett

Kuperberg, Arielle and Joseph E. Padgett. 2016. "The Role of Culture in Explaining College Student's Selection into Hookups, Dates, and Long-Term Romantic Relationships.” Journal of Social and Personal Relationships, 33(8): 1070-1096.

Made available courtesy of SAGE Publications: https://doi.org/10.1177/0265407515616876

Arielle Kuperberg and Joseph E. Padgett, "The Role of Culture in Explaining College Student's Selection into Hookups, Dates, and Long-Term Romantic Relationships,” Journal of Social and Personal Relationships (Volume 33 Issue 8) pp. 1070-1096. Copyright (c) 2015 Arielle Kuperberg and Joseph E. Padgett. Reprinted by permission of SAGE Publications.

***Note: This version of the document is not the copy of record.

\begin{abstract}
:
We analyze the Online College Social Life Survey, a survey collected between 2005 and 2011 of students $(N=22,454)$ at 22 U.S. colleges and universities and estimate whether students hooked up, dated, formed long-term romantic relationships, or did not form relationships while in college and their desire for these relationship opportunities. Students have equal rates of hooking up and dating. Men are more likely than women to have dated and hooked up and less likely to have formed a long-term relationship, although they are more likely to wish there were more opportunities to form long-term relationships. An examination of intimate partnering by sexual orientation, race, religious attendance, and Greek culture reveals distinct pattern that can be explained by cultural norms.
\end{abstract}

Keywords: Casual sex | college students | dates | hooking up | romantic relationships | sociology

\title{
Article:
}

"It is by now pretty well understood that traditional dating in college has mostly gone the way of the landline, replaced by 'hooking up'” declared a recent New York Times article (Taylor, 2013). Is that correct? Has the hookup replaced the date and long-term relationships on campus?

A hookup is a casual sexual encounter between two individuals that occurs outside of a romantic relationship but that does not necessarily involve penetrative sex (Bogle, 2008; Kuperberg \& Padgett, 2015). Dates are an older form of partnering that generally take place in public, involve some economic consumption, and carry the potential to become a long-term relationship (Kuperberg \& Padgett, 2015). Dates do not presume sexual contact like hookups but can include it; about one third of dates in our data included penetrative sex versus two thirds of hookups (Kuperberg \& Padgett, 2015). A long-term relationship is a lasting romantic and sexual relationship that in most cases implies a monogamous commitment with the potential to lead to 
cohabitation or marriage. All three intimate partnering types can lead to lasting relationships, pregnancy, childbearing, voluntary and natural abortions, physical and emotional pleasure, love, fulfillment, happiness, breakups, abuse, hurt feelings, and sexually transmitted infections.

Recent research found that approximately three fourths of college students reported at least one hookup (Eisenberg, 2001; Epstein, Calzo, Smiler, \& Ward, 2009; Grello, Welsh, \& Harper, 2006; Paul \& Hayes, 2002; Paul, McManus, \& Hayes, 2000), although college students reported fewer casual sex partners compared to noncollege educated young adults (Lyons, Manning, Giordano, \& Longmore, 2013). Some researchers indicate hookups have replaced dates on campus, while others found dates continue to be more common or that students engaged in both at roughly equal rates (Bogle, 2008; Bradshaw, Kahn, \& Saville, 2010; England, Fitzgibbons Shafer, \& Fogerty, 2007; Kuperberg \& Padgett, 2015; Regnerus \& Uecker, 2011). Hooking up and casual sex while in college has been found to be more common among men and members of fraternities and sororities and less common among students of color (Brimeyer \& Smith, 2012; Owen, Rhoades, Stanley, \& Fincham, 2010; Scott-Sheldon, Carey, \& Carey, 2008).

We add to prior literature by broadly exploring the role of culture in demographic partnering patterns, focusing on differences by gender, sexual orientation, race, religious service attendance, and Greek culture. We analyze a large recently collected data set to examine the relationship of these factors to hooking up, dating, long-term relationship formation, and not engaging in intimate partnering while in college. We also examine group-based differences in desire for more opportunities on campus to hookup, date, and form long-term relationships.

The role of culture in intimate partnering

In addition to biological and idiosyncratic differences in desire, personality, and attractiveness, romantic and sexual partnering is shaped by stratified cultural expectations or scripts and social norms. Cultural scripts are a type of cognitive "map” that provide a set of expectations that guide behavior and serve to orient individuals in a given social interaction and can shape whether and how college students engage in specific types of intimate partnering (Alksnis, Desmaris, \& Wood, 1996; Fontanella \& Gomes, 2015; Kuperberg \& Padgett, 2015; Plante, 2006; Rose \& Frieze, 1993). Collectively over time, groups of individuals develop dispositions or habitus to act in certain ways in specific situations (Bourdieu \& Johnson, 1993) that align with these scripts during romantic or sexual encounters. Scripts are shaped by culturally based social norms, which are collective expectations, shared values, or cultural "rules" about how individuals should behave in a given situation and which are collectively reinforced through social sanctions, which are negative or positive reactions by others in reaction to conformity to these norms (Gibbs, 1965). Norms are ideals and guide_-but may not always describe-typical behavior. These scripts and norms can vary by the social location (gender, race, religiosity, sexual orientation, education, etc.) of various individuals and the intersections of these factors (Collins, 2002; Dugger, 1988).

Social norms can shape desired partnership types, desired types of partners, and interact with market forces to shape structural opportunities to meet potential partners with complementary preferences in contexts that facilitate romantic and/or sexual partnering (Buss \& Schmitt, 1993). College campuses in particular facilitate partnering by exposing students to more sexually active 
unmarried young adults than other contexts, in an institutionally embedded, socially pre-selective setting where students are more likely to meet partners who share similar worldviews, leading to more compatible matches (Kimmel, 2008; Kuperberg \& Padgett, 2015; Laumann, Ellingson, Mahay, Paik, \& Youm, 2004). Student's participation in social networking via events on and off campus can further facilitate partnering by introducing students to a wider array of potential partners. Both the relative number of students within demographic categories and cultural norms related to the social desirability of certain groups as partners can affect structural partnering opportunities by constraining or expanding the number of potential partners available to members of certain social groups. Members of small visible minority groups or tokens may also alter partnering behavior as a result of their small demographic presence in conjunction with social norms regarding sexual behavior (Kanter, 1977). These factors interact in complex ways to shape partnering patterns by gender, sexual orientation, race, religiosity, and Greek culture. These five realms are associated with distinct cultural scripts and social norms affecting partnering behavior and desire and can potentially illustrate the effect of norms, networking, structure, social desirability, and tokenism on behavior.

\section{Gender and sexual orientation}

Gender is a structural factor, existing beyond individual desires and motives, which influences and interacts with other characteristics, yielding consequences at the individual and interactional levels (Collins, 2002; Risman \& Davis, 2013), perhaps most especially during sexual and romantic partnering. Recent research on college students found that while both genders expressed preference for dates over hookups, women were significantly more likely than men to prefer dates, with around 95\% of women preferring dates versus $77 \%$ of men (Bradshaw et al., 2010) and that just over half of students hooked up in the last year, with no significant differences by gender (Owen et al., 2010). After college many men continued hooking up outside of dating and established relationships, while women more often wanted hookups to develop into something more enduring (Bogle, 2008). Men generally were less interested than women of the same ages in settling down in stable relationships, had more permissive attitudes toward sex and casual sex, and were more likely to regret sexual inaction, while women were more likely to regret sexual action and to pursue sex within a relationship (England \& Bearak, 2014; Galperin et al., 2013 ; Laumann et al., 2004; Regnerus \& Uecker, 2011).

Sociologists and feminists argue that gender differences in romantic partnering preferences may result from, cause, or be reinforced by cultural double standards and social norms that result in women receiving negative social sanctions for engaging in casual sex while men receive social rewards (Armstrong, Hamilton, Armstrong, \& Seeley, 2014; England \& Bearak, 2014; Hamilton \& Armstrong, 2009; Kimmel, 2008). Evolutionary theory suggests a biological basis for sex differences in partnering preferences, indicating women may be more likely to prefer long-term relationships because they will have a greater personal investment in children resulting from sexual encounters due to the long-term commitment of pregnancy and nursing, while men also prefer long-term relationships but may be more interested than women in short-term sexual relationships with many partners, maximizing their number of potential offspring (Bailey, Gaulin, Agyei, \& Gladue, 1994; Buss \& Schmitt, 1993; Confer et al., 2010). 
Norms related to future expectations of romantic partnering also shape behavior (Sipsma, Ickovics, Lin, \& Kershaw, 2015) and vary by social location. Age-at-marriage norms may be related to norms regarding desired relationships for members of certain groups, regardless of individual intention to marry at a specific age or competing norms framing college as a time of sexual experimentation (Bogle, 2008; Rupp, Taylor, Regev-Messalem, Fogarty, \& England, 2014). Students expecting to marry earlier are less likely to engage in sexually permissive behavior (Carroll et al., 2007); similarly, members of groups that have earlier age-at-marriage norms may avoid hooking up in favor of long-term relationships and dates that may lead to them. Women expect to marry earlier than do men (Crissey, 2005) and due to awareness of age-related fertility issues, or the "ticking biological clock," women may be more interested in settling down earlier with a long-term partner and potentially having children (Lehrer \& Chen, 2011).

Since the vast majority of students in our data identify as heterosexual, based on past literature on norms and biological differences in partnering preferences by gender, we hypothesize that we will find that (Gender: $\mathrm{H}_{1}$ ) men were more likely than women to desire more opportunities for hookups and $\left(\mathrm{G}: \mathrm{H}_{2}\right)$ participate in hookups, while $\left(\mathrm{G}: \mathrm{H}_{3}\right)$ women were more likely to participate in long-term relationships and $\left(\mathrm{G}_{\mathrm{H}} \mathrm{H}_{4}\right)$ dates, which are associated with the possible initiation of long-term relationships. We also expect to find that ( $\mathrm{G}$ : $\mathrm{H}_{5}$ ) women desired more opportunities for long-term relationships and ( $\mathrm{G}$ : $\left.\mathrm{H}_{6}\right)$ dates compared to men.

On the other hand, long-term relationship formation among men may also be shaped by cultural norms and expectations regarding anticipated roles as primary breadwinners, which lead men without high wages to be considered "unmarriageable” (Harknett \& McLanahan, 2004). Women prefer older men and are less willing to marry younger men or men without a steady job and men prefer younger women and are more accepting of those without steady jobs, who earn less or who are less educated (Raley \& Bratter, 2004). Women may then date or form long-term relationships with older men who have already graduated college and are established in a career, leaving college men interested in long-term relationships with fewer opportunities for long-term partnering with their peers while completing their education. If this is the case, we would expect to see lower levels of long-term relationship formation but higher rates of men desiring longterm relationships, competing with $\mathrm{G}: \mathrm{H}_{5}$.

Men and women in college may also differ in partnering search strategies and rates, given an uneven sex ratio on campus, where women often outnumber men. Sex ratios affect partnering (Adkins, England, Risman, \& Ford, 2015; Kuperberg \& Padgett, 2015; Regnerus \& Uecker, 2011; Uecker \& Regnerus, 2010), and in contexts where one gender significantly outnumbers the other, the minority gender will have greater market value and therefore possess greater leverage and ability to have sex on their own terms (Baumeister \& Vohs, 2004; Regnerus \& Uecker, 2011). Prior research found that when women comprised a greater proportion of students on campus, they were less likely to go on traditional dates or have boyfriends, more likely to be sexually active, and had more sexual partners (Adkins et al., 2015; Uecker \& Regnerus, 2010). Therefore, $\left(\mathrm{G}: \mathrm{H}_{7}\right)$ on campuses with a higher proportion of women, we predict both men and women will have been less likely to go on dates or form long-term relationships and (G: $\left.\mathrm{H}_{8}\right)$ more likely to hookup. 
A stronger desire for casual partnering among men more generally may translate into differences in partnering by sexual orientation, given potential mismatches in partnering preferences of men and women that are less likely to occur among same-sex partners. Cultural dating scripts that emphasize casual sex among gay men and more intimate and emotional-based partnerships among lesbians (Klinkenberg \& Rose, 1994) may reflect or reinforce gender-based differences in partnering preferences and behavior. Prior research found heterosexual and nonheterosexual young adult women did not differ in casual sex experience or interest, but among men homosexuals were significantly more likely than heterosexuals to have had casual sex, despite similar levels of interest (Bailey et al., 1994; Eisenberg, Ackard, Resnick, \& Neumark-Sztainer, 2009), indicating a mismatch between interest and opportunities in the latter group. If male students who desire casual sex are partnering with female students who prefer long-term relationships, they may date instead of hookup as a compromise between competing desires for partnering types. Homosexual or bisexual men can instead partner with other men who also desire casual partnering (Bailey et al., 1994), leading to (Sexual Orientation: $\mathrm{H}_{1}$ ) higher hookup rates among homosexual versus heterosexual men. Conversely, (SO: $\left.\mathrm{H}_{2}\right)$ homosexual or bisexual women should have equal or lower rates of hooking up and ( $\mathrm{SO}: \mathrm{H}_{3}$ ) higher engagement in longterm relationships compared with heterosexual women, as a result of homogeneity in partnering preferences with mates.

Drawing from a larger pool of potential partners (SO: $\left.\mathrm{H}_{4}\right)$, bisexual students may engage in more partnering than either heterosexual or homosexual students. Past research found that women students who partnered with both genders reported more sexual partners than those with only same-sex or opposite-sex encounters, and men students who partnered with both genders had more partners than those with only opposite-sex sexual partners (Eisenberg, 2001). Bisexual students may have a lower desire for partnering opportunities on campus due to the relatively greater availability of partners they experience on campus. Gay and lesbian students may face partnering constraints from having fewer potential partners with compatible sexual orientations and therefore be more likely to desire relationship opportunities. However, the late 1990s and 2000s saw a widespread increase in the number of on campus spaces for gay, lesbian, and bisexual students (Fine, 2012), which can facilitate partnering among members of these groups. We predict therefore that ( $\mathrm{H}_{\text {: }} \mathrm{SO}_{5}$ ) bisexual students had lower desire for partnering opportunities than other groups, but make no prediction as to whether homosexual and heterosexual students differed in these desires.

Race

Race-based partner preference norms affect social desirability and, therefore, structural constraints on partnering. Women of color may participate less in partnering than White women (Race: $\mathrm{H}_{1}$ ) because White and Hispanic men in the U.S. tend to favor Whiteness in their sex partners (Laumann et al., 2004). This preference may be based on a desire for racial homogamy and can be affected by racism that emphasizes Black/White oppositional differences and places African Americans in the inferior position; African features on both women and men are considered less beautiful in American society (Collins, 2002, p. 89). Black women, as women, are especially valued based on their physical features and may also be categorized via stereotypical or controlling images (Collins, 2002). Images especially salient to college students can include the Black lady, the desexualized professional Black woman who is the modern 
version of a mammy, the women who "work twice as hard as everyone else," and "have no time for men or have forgotten how to treat them” (Collins, 2002, pp. 80-81).

Similarly, Asian American men have been portrayed as effeminate and asexual in popular culture, an image that emerged in the late 1800s/early 1900s U.S. in response to fears of Asian White miscegenation when Asian laborers began migrating to the U.S. and may have a hard time finding romantic and sexual partners because even Asian American women are likely to think of them in desexualized terms (Chan, 2001; Espiritu, 2008; Shek, 2007 ). This may leave Asian American men with fewer potential partners compared to other groups ( $\left.\mathrm{R}: \mathrm{H}_{2}\right)$, consistent with past research on hookups (Kimmel, 2008). For Asian women, controlling images as exotic and sexual (Nemoto, 2006) may instead increase hookup opportunities, (R: $\left.\mathrm{H}_{3}\right)$ leading to a decreased desire for these types of opportunities among Asian women.

Patterns of social desirability by race may intersect with gender norms and demographic representation to restrict the desire for certain types of partnering among visible racial minorities compared to White students. The relative number of people in a group brings about qualitative changes in group interactions (Kanter, 1977; Simmel, 1950). When a visible minority group is present in a token number (less than 15\%), they will sometimes receive, or think they are under, increased scrutiny and will feel excessively pressured to perform well regarding particular social standards as visible representatives of that group (Kanter, 1977). Previous research has found that, unlike White men, some Black men expect negative judgment by their peers for hooking up, in part because they felt under increased scrutiny due to their rare presence on campus (Kimmel, 2008). Black women may be resisting portrayals as the sexually promiscuous "jezebel, whore or 'hoochie”" (Collins, 2002, p. 81). Given sexual double standards that generally stigmatize women and reward men for casual sex, tokenism may restrict hookups (consistent with $\left.\mathrm{R}: \mathrm{H}_{1}\right)$ and desires for hookups among women of color $\left(\mathrm{R}: \mathrm{H}_{3}\right)$ as compared to White women but lead to no racial differences among men ( $\left.\mathrm{R}: \mathrm{H}_{4}\right)$.

Finally, academic achievement norms can indirectly affect partnering among college students. More academically focused students may reduce or forgo social activities that facilitate partnering to focus on their studies or may desire sexual encounters that do not require extensive time investment, such as hookups. A cultural emphasis on academic achievement among Asian American students, albeit not uniform across this group (Ngo \& Lee, 2007; Sue \& Okazaki, 1990; Warikoo \& Carter, 2009) may, consistent with R: H2, reduce participation in, and consistent with $\mathrm{R}: \mathrm{H}_{3}$, reduce their desire for intimate partnering while in college, regardless of individual grade point average (GPA) achieved. This emphasis, often attributed to parents, may result from selection into voluntary immigration among high-achieving Asian immigrants (Warikoo \& Carter, 2009) following U.S. immigration prioritization of professionals that in 1965 replaced the national origins quota system that previously restricted Asian immigration (Massey, 1981).

Religiosity

Religious norms about acceptable intimate relationships also affect partnering. Christianity, the dominant religion in the U.S., has a long history of sexual asceticism, stemming from early Christian beliefs that carnal pleasure was at odds with a spiritual life, and even marriage was 
second-best to the preferred lifestyle of celibacy (Coontz, 2006 ; Foucault, 1979). Although specific religious affiliations are unrelated to student's participation in dating or hooking up (Brimeyer \& Smith, 2012), more religious students desire a lower age at marriage (Fuller, Frost, \& Burr, 2015), and sex among the more religious is far more likely to occur within long-term relationships, less rapidly, after more commitment, and with fewer partners than less- or nonreligious individuals (Burdette, Ellison, Hill, \& Glenn, 2009; Laumann, Gagnon, Michael, \& Michaels, 1994; Regnerus \& Uecker, 2011), indicating that (Religiosity: $\mathrm{H}_{1}$ ) more religious students may hookup less but (Rel: $\mathrm{H}_{2}$ ) will not reduce their long-term relationships. Alternatively (Rel: $\mathrm{H}_{3}$ ), students who attend services more often may have fewer long-term relationships than those who attend less often because those without a partner may increase church attendance to increase social contact and meet others or because they are not as busy as those with a partner. Religious attendance can also provide a more extensive social network of acquaintances with similar values (Lima \& Putnam, 2010).Therefore, while strong religious beliefs may culturally discourage casual sex, religious service attendance embeds students in a specific network from which to draw partners, potentially leading religious attenders to (Rel: $\mathrm{H}_{4}$ ) date and (Rel: $\left.\mathrm{H}_{5}\right)$ form long-term relationships more than nonattenders.

\section{Greek culture}

Casual sex and the facilitation thereof is an established aspect and arguably a primary role of Greek culture on campus (Sanday, 2007). Fraternity and sorority membership and housing connects students to dense social networks through coed parties sponsored by these organizations, which enables meeting more potential partners. One study found that $44 \%$ of college students who had hooked up did so at a Greek party or event (Paul et al., 2000). Students who participate in Greek culture may (Greek culture: $\mathrm{H}_{1}$ ) hookup more because they are part of this culture and may join Greek organizations because they are interested in hooking up or in social networking more generally. Living in Greek housing may further facilitate casual sexual encounters $\left(\mathrm{Gr}: \mathrm{H}_{2}\right)$ since students have close access to Greek party culture and are less supervised compared to those living in dormitories and, especially, those living with parents, who typically act as a socially conservative force on relationship formation (Kimmel, 2008; Rosenfeld, 2007; Scott-Sheldon et al., 2008). Similar to students living in independent housing, students living in Greek housing may also be more socially desirable due to their perceived independence and the financial resources and/or status necessary to obtain these housing situations.

Campuses with more sororities and fraternities may have more opportunities for short-term partnering encounters due to more Greek-sponsored parties on campus that can facilitate partnering and shape sexual expectations of students, even for those who are not personally a member of a Greek organization (Sanday, 2007), potentially leading to (Gr: $\mathrm{H}_{3}$ ) higher engagement in hookups on campuses with more fraternities and sororities. This emphasis on casual sex in Greek culture may preclude long-term relationship formation that could limit hookup opportunities. Therefore, we predict that $\left(\mathrm{Gr}_{\mathrm{H}} \mathrm{H}_{4}\right)$ a greater Greek presence on campus and (Gr: $\left.\mathrm{H}_{5}\right)$ an individual's Greek membership would not increase, or may even preclude participation in, long-term relationships. 


\section{Data, variables, and method}

We analyzed the Online College Social Life Survey (OCSLS), which surveyed 24,131 college students at 22 colleges and universities in the U.S. between 2005 and 2011 . We collected all college-level measures from U.S. News and World Report, college websites, and correspondence with campus staff during June and July 2011, shortly after the completion of the OCSLS data collection. Students at a variety of college types were sampled, including three private research universities, nine public research universities, five regional comprehensive universities, four small liberal arts colleges including two that were religiously affiliated institutions, and one community college. Universities and colleges were drawn from throughout the U.S., with eight on the West Coast, six in the Northeast, five in the Midwest, two in the South, and one in the Southwest. The data collectors obtained approval from human subjects institutional review board at all colleges where data were collected.

\section{Participants and procedures}

Data were collected through a self-administered computer survey distributed to college students and included detailed information on respondent's partnering history. Response rates within these courses were over 99\% (Armstrong, England, \& Fogarty, 2012). Students were not compensated monetarily, although participation in this survey was a class assignment in most cases, with an alternative assignment available for students who did not want to participate. Colleges were selected out of convenience and surveys were distributed in classes taught by personal acquaintances of the data collector (see Armstrong et al., 2012; Kuperberg \& Padgett, 2015 for more details). Distribution primarily took place in introductory sociology and other courses focusing on gender, family, and sexuality, and approximately $80 \%$ of courses from which the sample were drawn were sociology courses, although the sample was almost 90\% nonsociology majors. Significant differences were not found between sociology majors and other students. The distribution of surveys in these courses may have resulted in the uneven sex ratio we find in our data, in which more students were found to be female compared to college students as a whole in those universities (Kuperberg \& Padgett, 2015). Distribution in introductory-level courses likely led to a disproportionate number of first year and second year students in the sample_-almost $60 \%$ of the sample_-who are more likely to take courses at this level.

\section{Measures}

Outcome variables. We focus on hookups, dates, and long-term relationships that formed since the student began college or whether the respondent has engaged in none of these types of relationships since starting college. Regarding hookups, students were prompted by being told "For this section, use whatever definition of hookup you and your friends generally use. It doesn't have to include sex to count if you and your friends would call it a hookup” and were then asked "Since you started college (counting during summers or during a term abroad) ... how many people have you hooked up with whom you didn’t know before that night?” and “ ... how many people have you hooked up with in the case where you were not already in a romantic relationship with the person but you did know him or her?” Regarding dates, respondents were asked "How many dates have you been on since starting college that involved going to a 
fraternity, sorority or dorm event?" and "How many dates have you been on since starting college that did not involve going to fraternity, sorority or dorm event?” Any number above 0 was used to designate that they had participated in that type of relationship while in college, and the values of both hookup questions were combined to calculate the total number of hookups, while the values of both date questions were combined to calculate the total number of dates. All four of these questions were originally truncated at 15 plus prior partners, and the total number of dates and partners are therefore truncated at 30 partners each. Respondents were also asked "Since starting college have you been in a romantic relationship that has lasted longer than 6 months?" with responses truncated at five. Those who did not participate in these three types of partnering were designated as having not engaged in partnering since starting college.

We also predict the desire for more opportunities for hookups, dates, and long-term relationships. Results are calculated from questions asking the respondent to agree, strongly agree, disagree, or strongly disagree with three questions related to these partnering opportunities; "I wish there were more opportunities for hooking up at my college," "I wish there were more opportunities for going on dates before a relationship is established at my college," and "I wish there were more opportunities for finding someone to have a relationship with at my college.” Responses were dichotomized into those who agreed or strongly agreed versus those who disagreed or strongly disagreed with each statement.

Predictor variables. At the individual level, key variables examined in our analysis include sexual orientation, race, religious service attendance, fraternity or sorority membership, and Greek versus dormitory, off campus, and parental living situations. Sexual orientation was determined from the question "What is your sexual orientation?" with "bisexual” and "unsure” combined into a single category. Religious service attendance was based on the question "How often did you typically attend religious services in the past year?" categorized as "no attendance" (from the respondents who selected "never"), "some” ("a few times per year"), and "frequent" (combining "1-3 times a month;" "once a week," and "more than once a week"). At the campus level, key variables include number of fraternities, number of sororities, and percent of students on campus who were female.

In models examining partnering participation, predictors additionally include measures of desire for all types of relationships. Desire for more opportunities to date, hookup, and form long-term relationships on campus measure both underlying biological and individualistic desire for these types of encounters and past experiences with those types of encounters. To further decompose past experience and its effect on desire, when predicting desire for partnering opportunities, we control for past number of encounter-type specific encounters (number of hookups when predicting desire for hookup opportunities, number of dates when predicting desire for dates, etc.). We additionally control for age, GPA over 3.5, average class size at the school, and number of students at the university to account for the possible effects discussed above and the nature of the data set. We divide students into 4 age-groups: 18-year olds, which captures freshman; 1920-year olds; 21-23-year olds who can legally buy alcohol but are still within the traditional age range of college students; and those 24 and older. 


\section{Analyses}

We estimated multilevel logistic random-effects regression models predicting having been on a date since starting college, hooking up since starting college, forming a long-term relationship since starting college, and having participated in none of these. We examined the effect of individual- and campus-level effects on past participation in these types of relationships and included an examination of the effect of desire for different types of relationships on past participation in each specific type of encounter. We also predicted desire for different types of relationships, controlling for the number of past relationships of that specific type, using both a squared and cubed term to account for nonlinearity in responses. In sensitivity tests (not shown, available from authors), we additionally estimated linear, quadratic, piecewise, and fraction polynomial models and found a cubic model most accurately resembled trends.

Results were estimated using the entire sample of students who were not missing information on outcome or predictor variables in our analysis $(N=1,677)$ yielding a final sample size of 22,454 students. In our other research with these data, results based on list-wise deletion did not substantially differ from results using multiple imputation methods. All models were calculated separately by gender. We found that controlling for contextual-level characteristics did not affect individual-level effects on partnering; therefore, we present models with both contextual- and individual-level effects.

Random-effects models include the consideration of clusters (in this case colleges) as sampled from a population and the ability to estimate covariates for and control for cluster-level (collegelevel) effects in order to clarify the effects of variables at lower levels of a hierarchical data structure (Rabe-Hesketh \& Skrondal, 2008). These types of multilevel models facilitate a more useful analysis of the effects of covariates at multiple levels of the data (Rabe-Hesketh \& Skrondal, 2008), allowing consideration of unobserved factors such as campus cultural differences or other variation across the schools sampled in the OCSLS. This allows inference beyond the schools in the sample and greater accuracy in terms of statistical significance compared to other types of models.

Our critical significance level was first set at $p<.001$ to account for our large sample size and to further account for the number of hypothesis tests that were conducted during the analyses the Bonferroni correction was applied to groups of tests. The Bonferroni correction divides the critical value to be used for any single test by the overall number of tests conducted. This corrected critical value is then used for each individual hypothesis test ensuring the cumulative, or family wise, Type I error rate remains below the desired level (Shaffer, 1995). The Bonferroni correction is implemented for the group of hypothesis tests in Table 1, two groups of hypothesis tests in Table 2, and for the tests in each model depicted in Tables 3 and 4 (further details below).

Table 1 displays descriptive statistics for the total sample as well as by gender; $t$-tests and $\chi^{2}$ analyses were used to determine whether women differ significantly from men using a Bonferroni adjusted $\alpha$ value of .00004 per test (.001/28). Table 2 describes partnering behavior of students since they started college as well as their desire for more opportunities for hookups, dates, and forming relationships and differences by gender. To determine whether gender 
differences in variables shown in Table 2 were significant, $t$-tests and $\chi^{2}$ analyses were conducted using a Bonferroni-adjusted $\alpha$ value of .00007 per test (.001/14). To compare the differences in variables within each group, as shown in Table 2 (e.g., do women's previous number of encounters differ by encounter type comparing hookups to dates), dependent samples $t$-tests and McNemar's $\chi^{2}$ tests of dependent proportions were conducted using a Bonferroni-adjusted $\alpha$ value of .00025 per test (.001/4) within each group.

Table 1. Descriptive statistics for sample difference by gender.

\begin{tabular}{|c|c|c|c|c|}
\hline & Total & Men & Women & $d$ \\
\hline \multicolumn{5}{|l|}{ Individual-level characteristics } \\
\hline Percent female & 68.79 & & & \\
\hline Heterosexual & 92.22 & 91.67 & 92.48 & 0.06 \\
\hline Homosexual & 2.79 & 5.11 & 1.74 & $-0.61^{*}$ \\
\hline Bisexual/not sure & 4.98 & 3.23 & 5.78 & $0.34^{*}$ \\
\hline White & 57.66 & 57.69 & 57.66 & 0.00 \\
\hline Black & 6.61 & 6.86 & 6.49 & -0.03 \\
\hline Asian & 15.18 & 16.90 & 14.40 & $-0.10^{*}$ \\
\hline $\begin{array}{l}\text { Hispanic } \\
\text { Other race }\end{array}$ & $\begin{array}{r}12.61 \\
7.94\end{array}$ & $\begin{array}{r}11.05 \\
7.51\end{array}$ & $\begin{array}{r}13.32 \\
8.13\end{array}$ & $\begin{array}{l}0.12^{*} \\
0.05\end{array}$ \\
\hline No religious attendance & 34.59 & 37.28 & 33.37 & $-0.09 *$ \\
\hline Some religious attendance & 41.37 & 40.26 & 41.88 & 0.04 \\
\hline High religious attendance & 24.04 & 22.46 & 24.76 & 0.07 \\
\hline Fraternity/sorority member & 12.16 & 13.43 & 11.58 & -0.09 \\
\hline Housing dorm/on campus & 48.00 & 47.38 & 48.29 & 0.02 \\
\hline Housing fraternity/sorority & 3.32 & 4.44 & 2.81 & $-0.26^{*}$ \\
\hline Housing off campus & 34.55 & 34.09 & 34.76 & 0.02 \\
\hline Housing parents & 14.13 & 14.09 & 14.15 & 0.00 \\
\hline Age 18 & 20.41 & 17.24 & 21.85 & $0.16^{*}$ \\
\hline Age 19-20 & 45.17 & 45.81 & 44.88 & -0.02 \\
\hline Age $21-23$ & 27.18 & 29.16 & 26.29 & $-0.08^{*}$ \\
\hline Age $24+$ & 7.24 & 7.79 & 6.99 & -0.07 \\
\hline $\mathrm{GPA}>3.5$ & 24.83 & 21.92 & 26.15 & $0.13^{*}$ \\
\hline \multicolumn{5}{|l|}{ Campus characteristics } \\
\hline \% Student body female & 51.82 & 51.42 & 52.01 & $0.10^{*}$ \\
\hline $\begin{array}{l}\text { \# Fraternities at institution } \\
\text { \# Sororities at institution }\end{array}$ & $\begin{array}{l}16.85 \\
12.88\end{array}$ & $\begin{array}{l}16.98 \\
12.86\end{array}$ & $\begin{array}{l}16.79 \\
12.88\end{array}$ & $\begin{array}{r}-0.03 \\
0.00\end{array}$ \\
\hline Average \# students per class & 32.60 & 32.58 & 32.61 & 0.01 \\
\hline Institution $<10,000$ students & 22.57 & 23.75 & 22.04 & -0.05 \\
\hline Institution $10,000-24,999$ students & 57.49 & 57.14 & 57.65 & 0.01 \\
\hline Institution $25,000+$ students & 19.94 & 19.11 & 20.31 & 0.04 \\
\hline$N$ & 22,454 & 7,007 & 15,447 & \\
\hline
\end{tabular}

Note. Hypothesis tests conducted using a Bonferroni-adjusted $\alpha$ value of .00004 per test $\left(.001 / 28 ;{ }^{*} p<00004\right)$. Percent of sample is given except for continuous variables, which are listed as "\# ..." in the row label.

Because of the influence of the large sample size on null hypothesis tests of significance, many effects examined were found to be significant but may not represent important substantive differences in behavior. To better assess the magnitude and practical significance of the effects identified in Tables 1 and 2, standardized effect sizes are also provided. For continuous variables the standardized effect sizes were calculated as:

$$
d=\frac{\mu_{1}-\mu_{2}}{\sqrt{\frac{\left(n_{1}-1\right) S_{1}^{2}+\left(n_{2}-1\right) S_{2}^{2}}{n_{1}+n_{2}-2}}},
$$


where $\mu, n$, and $S^{2}$ are the sample number, mean, and variances, respectively, for the groups being compared (Borenstein, Hedges, Higgins, \& Rothstein, 2009). For dichotomous categorical variables, effect sizes were calculated as

$$
d=L_{\mathrm{OR}} \frac{\sqrt{3}}{\pi},
$$

where, $L$ or is the natural logarithm of the odds ratio calculated from the portions of each group and $\pi=3.14159$ (Hasselblad \& Hedges, 1995). Cohen (1988) outlined interpretive criteria of small ( $d<.20)$, medium $(d=.50)$, and large $(d>.80)$ for gauging the size of $d$ but recommended great caution in using these criteria. Along with Cohen, subsequent researchers have recommended that the magnitude of effect sizes be gauged relative to the area being studied, specific methods deployed, and the distribution of effect sizes for comparable outcome measures and treatments (Cohen, 1988; Ellis, 2010; McCartney \& Rosenthal, 2000). Effect sizes are most useful for understanding the magnitude of differences relative to the magnitude of other effects analyzed within this study.

Table 2. Engagement in and desire for hookups, dates, and LTR (percent, unless described as number).

\begin{tabular}{|c|c|c|c|c|}
\hline & \multirow{2}{*}{$\frac{\text { Total }}{M(S D)}$} & \multirow{2}{*}{$\frac{\text { Men }}{M(S D)}$} & \multirow{2}{*}{$\begin{array}{l}\text { Women } \\
M(S D)\end{array}$} & \multirow[b]{2}{*}{$d$} \\
\hline & & & & \\
\hline Hooked up & 62.19 & 64.64 & 61.09 & $-0.08^{*}$ \\
\hline Dated & 60.97 & 63.64 & 59.76 & $-0.09 *$ \\
\hline Had relationship & 51.26 & 43.53 & 54.77 & $0.25^{*}$ \\
\hline Dated, hooked up, or LTR & 88.70 & 87.18 & 89.38 & $0.12^{*}$ \\
\hline No partnering activity & 11.30 & 12.82 & 10.62 & - \\
\hline Dated, hooked up, and formed LTR & 25.32 & 23.51 & 26.15 & $0.08^{*}$ \\
\hline $\begin{array}{l}\text { Dated and hooked up } \\
\text { Hooked up but no date, no LTR }\end{array}$ & $\begin{array}{r}48.80 \\
8.19\end{array}$ & $\begin{array}{r}51.55 \\
8.93\end{array}$ & $\begin{array}{r}47.56 \\
7.86\end{array}$ & $\begin{array}{l}-0.09 * \\
-0.08\end{array}$ \\
\hline Dated or formed LTR, but no hookup & 26.50 & 22.55 & 28.30 & $0.17^{*}$ \\
\hline Number of hookups & $4.12(5.98)$ & $5.06(6.99)$ & $3.70(5.4 I)$ & $-0.23^{*}$ \\
\hline Number of dates & $3.50(5.10)$ & $4.30(5.99)$ & $3.14(4.60)$ & $-0.23^{*}$ \\
\hline Number of LTRs & $0.90(1.30)$ & $0.76(1.24)$ & $0.96(1.32)$ & $0.15^{*}$ \\
\hline Desire for more opportunities for hookups & 27.14 & 48.47 & 17.46 & $-0.82^{*}$ \\
\hline Desire for more opportunities for dates & 66.50 & 66.05 & 66.71 & 0.02 \\
\hline Desire for more opportunities for LTRs & 68.04 & 70.81 & 66.78 & $-0.10^{*}$ \\
\hline Within-group comparisons & d & d & D & \\
\hline Hooked up-dated & 0.03 & 0.02 & 0.03 & \\
\hline $\begin{array}{l}\text { Hooked up but no date, no LTR-dated or LTR, } \\
\text { no hookup }\end{array}$ & $-0.77^{*}$ & $-0.60^{*}$ & $-0.84^{*}$ & \\
\hline Number of hookups-number of dates & $0.11^{*}$ & $0.13^{*}$ & $0.1 I^{*}$ & \\
\hline $\mathrm{N}$ & 22,454 & 7,007 & 15,447 & \\
\hline
\end{tabular}

Note. For gender differences, hypothesis tests were conducted using a Bonferroni-adjusted $\alpha$ value of $* p<.00007$ per test $(.001 / 14=.00007)$. For encounter differences within groups, hypothesis tests were conducted using a Bonferroni-adjusted $\alpha$ value of $* p<.00025$ per test $(.001 / 4=.00025)$. Percent of sample is given except for variables described as numbers in the row label. $M=$ mean, $S D=$ standard deviation; LTR = long-term relationship. 


\section{Results}

Table 2 presents total and gender-specific rates of relationship experience and desire. Just over $60 \%$ of all respondents reported having hooked up since starting college (62.19\%), a similar portion reported having been on a traditional date (60.97\%), and about half reported having had a long-term relationship (51.26\%). While rates of participation in dating and hooking up did not significantly differ, respondents had significantly more past hookups $(M=4.12, S D=5.98)$ than dates $(M=3.50, S D=5.10)$ since starting college, although the effect size is small $(d=.11)$. The majority of respondents (88.70\%) engaged in at least one of these three partnering activities since beginning college, and few respondents (11.30\%) reported engaging in none of them, with one quarter of respondents (25.32\%) participated in all three. Students were significantly less likely to participate in hookups to the exclusion of other types of partnering (8.19\%) than they were to have had a date or long-term relationship but no hookup (26.50\%) with a large effect size of $d=-.77$.

Women were less likely to hookup (61.09\%) than men (64.64\%), but the effect size was small $(d=-.08)$, and this finding confirms our prediction in $\mathrm{G}$ : $\mathrm{H}_{2}$. Also in line with $\mathrm{G}$ : $\mathrm{H}_{2}$, the number of past hookups for women $(M=3.70, S D=5.41)$ was significantly lower than those for men $(M=5.06, S D=6.99)$ with a gender difference of a moderate $d=-.23$. Women also had a moderately lower $(d=-.23)$ number of dates $(M=3.14$, $S D=4.60)$ compared to men $(M=$ $4.30, S D=5.99)$, and a smaller proportion of women $(59.76 \%)$ versus men $(63.64 \%)$ had dated since starting college, a small $(d=-.09)$ but significant effect. These findings contradict $\mathrm{G}_{\mathrm{H}} \mathrm{H}_{4}$, in which we predicted women would date more than men. Approximately half of men (51.55\%) and women (47.56\%) alike had both dated and hooked up. In line with G: H3, women (54.77\%) were significantly more likely than men (43.53\%) to have reported having been in a long-term relationship since starting college, with a larger in magnitude difference $(d=.25)$ compared to gender differences in dating and hooking up participation. Women also reported a significantly higher $(M=.96, S D=1.32)$ number of previous relationships than men $(M=.76, S D=1.24)$, with a small in magnitude $(d=.15)$ difference.

Confirming $\mathrm{G}$ : $\mathrm{H}_{1}$, a much smaller portion of women (17.46\%) than men (48.47\%) indicated a desire for more opportunities to hookup, a significant difference that is quite large $(d=-.82)$, particularly as compared to other differences by gender. The desire for more opportunities to form long-term relationships was more common among men (70.81\%) than women (66.78\%), a small $(d=-.10)$ but significant difference that contrasts with $H_{:} G_{5}$, which predicted women would be more likely to desire long-term relationships. The gender difference in the portion of respondents indicating a desire for more opportunities to date was not significant, with many men (66.05\%) and women (66.71\%) desiring more date opportunities. This contradicts G: H6, where we predicted women would be more likely to desire date opportunities. For both genders, long-term relationships were the most common type of relationship desired, and hookups were

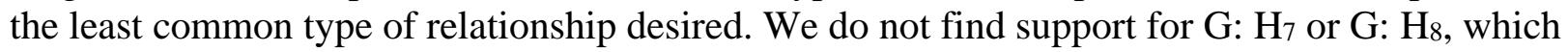
predicted significant differences in behavior by sex ratios in school, and we find no significant effects of campus sex ratios on partnering behavior (see Table 3). 
Table 3. Multilevel logistic random effects models predicting encounter experience, odds ratios.

\begin{tabular}{|c|c|c|c|c|c|c|c|c|}
\hline \multirow[b]{2}{*}{ Encounter experience } & \multicolumn{2}{|c|}{ Hooked-up } & \multicolumn{2}{|c|}{ Dated } & \multicolumn{2}{|c|}{$6+$ Month relationship } & \multicolumn{2}{|c|}{ No partnering } \\
\hline & Men & Women & Men & Women & Men & Women & Men & Women \\
\hline \multicolumn{9}{|l|}{ Individual-level characteristics } \\
\hline Desire for hookups & $2.01 *$ & $1.34^{*}$ & 1.18 & 0.99 & 0.83 & $0.7 I^{*}$ & $0.7 I^{*}$ & 0.95 \\
\hline $\begin{array}{l}\text { Desire for dates } \\
\text { Desire for LTR }\end{array}$ & $\begin{array}{l}0.93 \\
1.32\end{array}$ & $\begin{array}{l}1.29 * \\
1.97 *\end{array}$ & $\begin{array}{l}1.19 \\
1.50^{*}\end{array}$ & $\begin{array}{l}1.16 \\
1.82 *\end{array}$ & $\begin{array}{l}0.79 \\
0.47^{*}\end{array}$ & $\begin{array}{l}0.69^{*} \\
0.34^{*}\end{array}$ & $\begin{array}{l}1.27 \\
1.13\end{array}$ & $\begin{array}{l}1.11 \\
1.20\end{array}$ \\
\hline $\begin{array}{l}\text { Homosexual } \\
\text { Bisexual/not sure }\end{array}$ & $\begin{array}{l}1.84^{*} \\
1.48\end{array}$ & $\begin{array}{l}1.01 \\
1.35\end{array}$ & $\begin{array}{l}1.07 \\
1.05\end{array}$ & $\begin{array}{l}1.20 \\
1.30\end{array}$ & $\begin{array}{l}0.49 * \\
0.46 *\end{array}$ & $\begin{array}{l}1.14 \\
1.10\end{array}$ & $\begin{array}{l}1.14 \\
1.28\end{array}$ & $\begin{array}{l}1.03 \\
0.88\end{array}$ \\
\hline Black & 1.12 & $0.57^{*}$ & 0.89 & 0.86 & 0.87 & 0.77 & 1.22 & $1.90^{*}$ \\
\hline Asian & $0.37 *$ & $0.42^{*}$ & $0.60^{*}$ & $0.73^{*}$ & $0.68 *$ & 0.87 & $2.97^{*}$ & $2.57^{*}$ \\
\hline Hispanic & 0.85 & $0.70^{*}$ & 0.95 & 0.86 & 1.07 & 1.16 & 1.04 & 1.30 \\
\hline Other race & 0.86 & $0.73^{*}$ & 0.81 & 0.87 & 1.05 & 0.99 & 1.33 & 1.48 \\
\hline $\begin{array}{l}\text { Some religious attendance } \\
\text { High religious attendance }\end{array}$ & $\begin{array}{l}1.34^{*} \\
0.74\end{array}$ & $\begin{array}{l}1.00 \\
0.64^{*}\end{array}$ & $\begin{array}{l}1.37 * \\
1.11\end{array}$ & $\begin{array}{l}1.15 \\
1.01\end{array}$ & $\begin{array}{l}1.15 \\
1.03\end{array}$ & $\begin{array}{l}1.08 \\
0.91\end{array}$ & $\begin{array}{l}0.63^{*} \\
0.98\end{array}$ & $\begin{array}{l}0.90 \\
1.39 *\end{array}$ \\
\hline $\begin{array}{l}\text { Fraternity/sorority member } \\
\text { Housing fraternity/sorority }\end{array}$ & $\begin{array}{l}2.84^{*} \\
2.14\end{array}$ & $\begin{array}{l}2.03^{*} \\
1.77\end{array}$ & $\begin{array}{l}2.59 * \\
1.87\end{array}$ & $\begin{array}{l}2.24^{*} \\
1.57\end{array}$ & $\begin{array}{l}1.09 \\
0.98\end{array}$ & $\begin{array}{l}1.06 \\
1.20\end{array}$ & $\begin{array}{l}0.42^{*} \\
0.26\end{array}$ & $\begin{array}{l}0.40^{*} \\
0.43\end{array}$ \\
\hline Housing off campus & $1.56 *$ & $1.45^{*}$ & $1.88^{*}$ & $1.52^{*}$ & $1.62 *$ & $1.64^{*}$ & $0.52^{*}$ & $0.54^{*}$ \\
\hline $\begin{array}{l}\text { Housing parents } \\
\text { Age 19-20 }\end{array}$ & $\begin{array}{l}0.86 \\
1.23\end{array}$ & $\begin{array}{l}0.87 \\
1.27 *\end{array}$ & $\begin{array}{l}1.01 \\
1.51^{*}\end{array}$ & $\begin{array}{l}1.13 \\
1.65^{*}\end{array}$ & $\begin{array}{l}1.13 \\
1.86^{*}\end{array}$ & $\begin{array}{l}1.38^{*} \\
2.25^{*}\end{array}$ & $\begin{array}{l}1.21 \\
0.71\end{array}$ & $\begin{array}{l}0.96 \\
0.56^{*}\end{array}$ \\
\hline $\begin{array}{l}\text { Age } 21-23 \\
\text { Age } 24+\end{array}$ & $\begin{array}{l}1.73^{*} \\
1.34\end{array}$ & $\begin{array}{l}1.97^{*} \\
1.11\end{array}$ & $\begin{array}{l}2.86^{*} \\
1.85^{*}\end{array}$ & $\begin{array}{l}2.85^{*} \\
1.43^{*}\end{array}$ & $\begin{array}{l}4.43^{*} \\
6.13^{*}\end{array}$ & $\begin{array}{l}4.90^{*} \\
5.06^{*}\end{array}$ & $\begin{array}{l}0.30^{*} \\
0.50\end{array}$ & $\begin{array}{l}0.27^{*} \\
0.59\end{array}$ \\
\hline GPA $3.5+$ & $0.65^{*}$ & $0.66^{*}$ & 0.81 & $0.78^{*}$ & 1.25 & 1.03 & 1.18 & $1.41^{*}$ \\
\hline \multicolumn{9}{|l|}{ Campus characteristics } \\
\hline \%Female & 1.00 & 0.98 & 0.98 & 0.97 & 0.99 & 1.00 & 1.02 & 1.02 \\
\hline \# Fraternities at institution & 1.00 & 0.99 & 1.00 & 0.99 & 1.00 & 1.00 & 1.02 & 1.01 \\
\hline \# Sororities at institution & 1.02 & 1.02 & 1.00 & 1.00 & 0.98 & 0.99 & 0.97 & 0.98 \\
\hline \# Students per class & 0.97 & 0.97 & 0.99 & 0.99 & 1.02 & 1.02 & 1.02 & 1.00 \\
\hline $10,000-24,999$ students & 0.89 & 0.94 & 0.94 & 0.93 & 0.92 & 1.16 & 1.05 & 0.97 \\
\hline $25,000+$ students & 0.80 & 1.01 & 0.97 & 1.23 & 1.01 & 1.26 & 0.89 & 0.85 \\
\hline$N$ & 7,007 & 15,447 & 7,007 & 15,447 & 7,007 & 15,447 & 7,007 & 15,447 \\
\hline
\end{tabular}

Note. Hypothesis tests were conducted using a Bonferroni-adjusted $\alpha$ value of $p<.00004$ per test $(.001 / 25)$ within each model. GPA = grade point average; LTR = long-term relationship.

Partnering experiences and desire for partnering opportunities

Table 3 presents the results of models predicting past experience in each type of partnering activity while in college and no partnering while in college. Desire for hookup opportunities was positively related to having hooked up for men and women. On the other hand, desire for dates was not related to past date experience, and desire for more relationship opportunities was negatively related to having been in a long-term relationship for both men and women. Perhaps fewer romantic relationships satisfy desire for that type of partnering. Among both men and women, desire for relationship opportunities was positively related to having engaged in dating and for women was also positively related to having had hooked up, perhaps because individuals seeking long-term relationships engaged in these other types of partnering during their search. Women who have hooked up were also more likely to desire opportunities for dates, perhaps for similar reasons. Men who do not desire hooking up opportunities were significantly less likely to have formed any type of partnership on campus.

Table 4 presents predictors of desire for different types of relationships. Past experiences with specific relationship types are associated with desire for opportunities for those types of relationships in a nonlinear fashion. Figure 1 presents odds ratios for the effect of number of past partners on desire for date and hookup partnering opportunities. Among those with fewer past partners (0-8), desire was positively associated with the number of partners. This relationship 
plateaus at 9-15 past partners and becomes negative afterward until very high numbers of past partners, which was associated with slightly higher levels of desire for partnering. Conversely, those who have had at least one long-term relationship were consistently less likely than those who have none to desire more opportunities for a relationship (see Figure 2), and desire declined with more relationships, although not entirely linearly. While men and women had at times differing overall levels of desires for partnering types, the impact of past experience on desire for partnering opportunities showed a remarkably similar pattern for both genders.

Table 4. Multilevel logistic random effects models predicting desire for additional partnering opportunities, odds ratios.

\begin{tabular}{|c|c|c|c|c|c|c|}
\hline \multirow[b]{2}{*}{ Encounter experience } & \multicolumn{2}{|c|}{ Hookups } & \multicolumn{2}{|c|}{ Dates } & \multicolumn{2}{|c|}{$\begin{array}{l}6+\text { Month } \\
\text { relationships }\end{array}$} \\
\hline & Men & Women & Men & Women & Men & Women \\
\hline \multicolumn{7}{|l|}{ Individual-level characteristics } \\
\hline $\begin{array}{l}\text { \# of previous relationship type-specific } \\
\text { partners }\end{array}$ & $1.25^{*}$ & $1.20^{*}$ & $1.15^{*}$ & $1.16^{*}$ & $0.20^{*}$ & $0.14^{*}$ \\
\hline $\begin{array}{l}\text { \# of previous relationship type-specific } \\
\text { partners squared }\end{array}$ & $0.98^{*}$ & $0.99 *$ & $0.99 *$ & $0.99 *$ & $2.22^{*}$ & $2.32^{*}$ \\
\hline $\begin{array}{l}\text { \# of previous relationship type-specific } \\
\text { partners cubed }\end{array}$ & $1.00^{*}$ & $1.00^{*}$ & 1.00 & $1.00^{*}$ & $0.90^{*}$ & $0.90^{*}$ \\
\hline Homosexual & 0.92 & 1.71 & 1.37 & 0.74 & $2.18^{*}$ & 1.09 \\
\hline Bisexual/not sure & 1.16 & 1.31 & 1.03 & 1.01 & 0.98 & 0.99 \\
\hline Black & 1.29 & $1.52^{*}$ & 1.16 & 1.35 & 1.15 & 0.98 \\
\hline Asian & $1.64^{*}$ & $1.47^{*}$ & $1.76^{*}$ & $1.44^{*}$ & 1.15 & 0.98 \\
\hline Hispanic & 1.24 & 1.23 & 1.33 & 1.04 & 1.11 & 0.83 \\
\hline Other race & 1.09 & 1.16 & 1.32 & 1.13 & 0.97 & 0.93 \\
\hline Some religious attendance & 0.84 & 0.95 & 1.09 & 1.13 & 1.03 & 1.12 \\
\hline High religious attendance & $0.7 I^{*}$ & 0.84 & 1.05 & 1.17 & 0.96 & 1.01 \\
\hline Fraternity/sorority member & 1.02 & 1.01 & 0.98 & $1.45^{*}$ & 1.08 & $1.52^{*}$ \\
\hline Housing fraternity/sorority & 0.81 & 0.59 & 0.85 & 1.28 & 0.87 & 1.21 \\
\hline Housing off campus & 0.84 & $0.7 I^{*}$ & 0.77 & 0.82 & 0.90 & 0.91 \\
\hline Housing parents & 1.11 & 0.93 & 0.94 & 0.79 & 1.06 & 0.88 \\
\hline Age 19-20 & 0.86 & 0.94 & 1.23 & 1.04 & 1.35 & $1.49^{*}$ \\
\hline Age $21-23$ & 0.84 & 0.78 & 1.21 & 0.97 & $1.78^{*}$ & $1.74^{*}$ \\
\hline Age 24+ & 0.70 & 0.76 & 1.01 & $0.65^{*}$ & 1.15 & 0.91 \\
\hline GPA $3.5+$ & 0.87 & $0.78^{*}$ & 1.15 & 0.98 & 1.04 & 0.98 \\
\hline \multicolumn{7}{|l|}{ Campus characteristics } \\
\hline$\%$ Female & 0.97 & 0.98 & 0.99 & 1.00 & 0.97 & 0.98 \\
\hline \# Fraternities at institution & 1.00 & 1.00 & 0.99 & 0.98 & 0.99 & 0.99 \\
\hline \# Sororities at institution & 0.96 & 0.97 & 1.01 & 1.04 & 1.02 & 1.04 \\
\hline \# Students per class & 1.04 & 1.00 & 1.01 & 0.96 & 1.01 & 0.97 \\
\hline $10,000-24,999$ students & 0.91 & 0.87 & 0.77 & 0.75 & 0.72 & 0.71 \\
\hline $25,000+$ students & 1.07 & 1.01 & 0.83 & 0.65 & 0.81 & 0.71 \\
\hline$N$ & 7,007 & 15,447 & 7,007 & 15,447 & 7,007 & 15,447 \\
\hline
\end{tabular}

Note. Hypothesis tests were conducted using a Bonferroni-adjusted $\alpha$ value of $* p<.00004$ per test $(.001 / 25)$ within each model. GPA = grade point average.

Sexual orientation, race, religiosity, and Greek culture

Homosexual and bisexual men were less than half as likely as heterosexual men to have been in a long-term relationship since starting college, while homosexual men were $84 \%$ more likely to have hooked up than heterosexual men, confirming SO: $\mathrm{H}_{1}$ for homosexual men but not our expectations for higher hookup rates among bisexual men. The likelihood of having engaged in 
hookups, dates, or long-term relationships was equal for homosexual or bisexual women compared to heterosexual women, confirming $\mathrm{SO}: \mathrm{H}_{2}$ in which we predicted equal rates or lower rates of hookup engagement among homosexual and bisexual women. SO: $\mathrm{H}_{3}$, which predicted more long-term relationships among homosexual women, $\mathrm{SO}: \mathrm{H}_{4}$, which predicted more partnering among bisexuals, and SO: $\mathrm{H}_{5}$, which predicted less partnering opportunity desire among bisexuals were not supported by these data. Homosexual men were more than twice as likely to desire long-term relationship opportunities as heterosexual men, which we did not predict but were not different in their likelihood of desiring hookup opportunities.

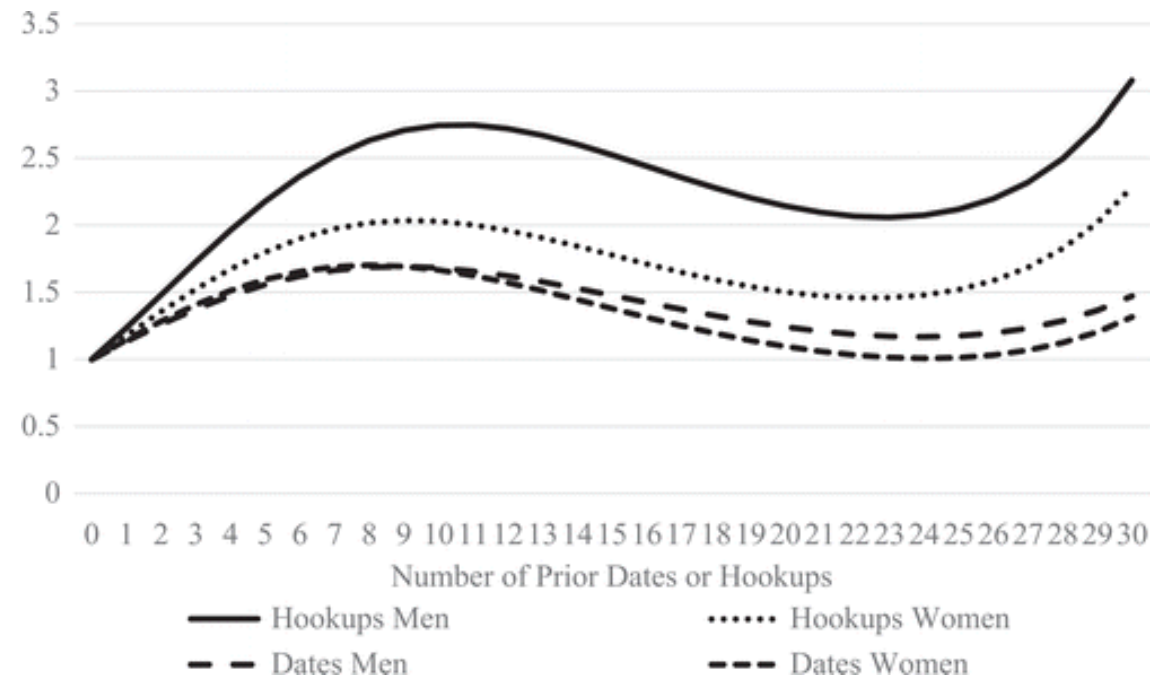

Figure 1. Predicted probability of desire for more opportunities for dates/hookups by past experience with relationship type (odds ratios).

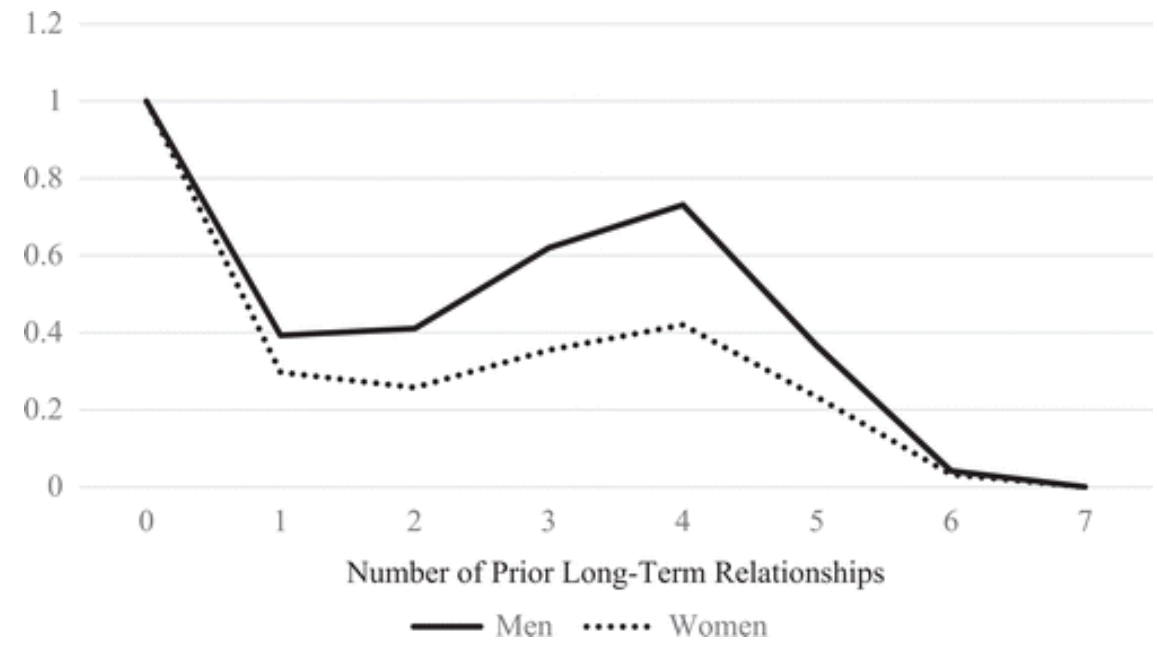

Figure 2. Predicted probability of desire for more opportunities for long-term relationships by past number of relationships (odds ratios). 
Confirming $\mathrm{R}: \mathrm{H}_{1}$ for hookups, all women in minority racial/ethnic groups were less likely to have engaged in hookups compared to White women. Black women were $57 \%$ as likely as White women to engage in hookups and 90\% more likely to have never engaged in partnering on campus. In line with $\mathrm{R}: \mathrm{H}_{2}$, Asian women had the lowest rates of both dating and hooking up and were over 2.5 times as likely as White women to have never engaged in partnering on campus. In contrast with R: $\mathrm{H}_{3}$, where we predicted women of color would be less likely to desire relationship opportunities due to their token status on campus, Black and Asian women were more likely than White women to desire more opportunities to hookup on campus, and Asian women were also more likely to desire date opportunities but not long-term relationship opportunities. Among men, there is little racial variation in hooking up, dating, forming longterm relationships, or desire for relationships, consistent with $\mathrm{R}$ : $\mathrm{H}_{4}$, except that compared to White men, Asian men are less likely to engage in dating, hooking up, or forming long-term relationships and are 2.97 times as likely to have never formed a partnership, consistent with R: $\mathrm{H}_{2}$. Asian men were also about $60 \%$ more likely than White men to desire hookup opportunities and $76 \%$ more likely to desire dating opportunities.

Women who attend religious services at least once a month were least likely to have hooked up, although they exhibited no difference in dating or forming long-term relationships compared to students who never attended religious services, giving mixed support to Rel: $\mathrm{H}_{1}$ for women. Women who attended religious services frequently were significantly more likely than those who never attended services to have formed no relationships while on campus consistent with Rel: $\mathrm{H}_{1}$, while occasional attenders were equally likely as nonattenders to have formed these types of relationships. On the other hand, among men, in opposition to the patterns predicted in Rel: $\mathrm{H}_{1}$ and in line with predictions in Rel: $\mathrm{H}_{4}$, sometimes service attenders were significantly more likely to have hooked up and dated than nonattenders and were significantly less likely to have never formed a relationship. Men's hooking up and dating experience therefore has a reverse ushaped relationship to religious attendance. Men who attended services frequently had significantly lower desire for hookup opportunities, perhaps a cause of the u-shaped relationship in hookup participation. Consistent with Rel: $\mathrm{H}_{2}$ and contradicting Rel: $\mathrm{H}_{3}$ and Rel: H5, we find no difference in long-term relationship formation by religious attendance.

Membership in a fraternity or sorority was correlated with a significantly higher rate of engaging in both hookups and dates and men in fraternities were 2.8 and 2.6 times as likely as nonmembers to engage in hookups and dates, respectively, while women in sororities were around twice as likely to have hooked up and 2.24 times more likely to have dated compared to nonmembers. This confirms Gr: $\mathrm{H}_{1}$, which predicted Greek members would hookup more frequently. Reflecting the short-term nature of partnering norms in Greek culture, members were no more likely than nonmembers to have been in a long-term relationship, in line with predictions in Gr: $\mathrm{H}_{5}$. Both male and female members of Greek organizations were only about $40 \%$ as likely as those who were not members to have never engaged in partnering while on campus. Women in sororities were around 50\% more likely than nonmembers to want more opportunities for dates; men did not differ in desire for partnering opportunities by Greek membership. In contrast with $\mathrm{Gr}: \mathrm{H}_{2}, \mathrm{Gr}$ : $\mathrm{H}_{3}$, and $\mathrm{Gr}_{\text {: }} \mathrm{H}_{4}$, Greek housing and number of sororities and fraternities on campus were not related to participation in or desire for opportunities for hookups, dates, or long-term relationships on campus. 


\section{Discussion}

Romantic partnering patterns while on campus have implications for a range of demographic outcomes and are of relevance to all those who attend college, which is the majority of young adults (Bureau of Labor Statistics, 2014). We found around 60\% of our sample had dated and a similar proportion had hooked up, making further study of these forms of partnering germane to the majority of college students. Hookup rates were somewhat lower than the $70-75 \%$ rate found in prior research (Eisenberg, 2001; Epstein et al., 2009; Grello et al., 2006; Paul \& Hayes, 2002; Paul et al., 2000), consistent with our sampling technique, which resulted in an oversampling of college freshman who have less time while in college to have hooked up. While students do have more hookup partners than dating partners, their essentially equal rates of participation in these types of partnering, the fact that only $8 \%$ have exclusively participated in hookups to the exclusion of other partnering forms, and the significantly lower likelihood of students exclusively hooking up versus exclusively dating or forming long-term relationships on campus, belie recent media reports declaring that the date has been replaced by the hookup on campus.

Examining selection into different types of relationships also suggests disparate partnering patterns among college students, a point frequently overlooked when college graduates or those who attend college are treated as homogenous groups in academic research and media reports. Examining selection into intimate partnering and comparing results with those regarding desire for partnering opportunities illuminates the degree to which culture interacts with structure in shaping partnering patterns. Table 5 presents a summary table of hypotheses, the theoretical explanations that led to those hypotheses and whether or not they are supported by the findings of our analyses.

Groups that both partner less and desire more opportunities for partnering likely face constraints related to partner availability or engaging in that type of partnering, which are shaped by cultural norms. Fewer men than women participated in long-term relationships but not necessarily because they did not want to, and men were significantly more likely than women to desire more opportunity for long-term relationships, indicating these patterns may be affected by norms surrounding the social desirability of older and more economically established men. Men may also be conforming to societal expectations that they be more interested in casual sex (Armstrong et al., 2014; England \& Bearak, 2014; Hamilton \& Armstrong, 2009; Kimmel, 2008) and/or succumbing to a form of pluralistic ignorance resulting from the (false) perception that other men are more interested in casual sex than they are themselves.

Similarly, homosexual men were more likely to engage in hookups and less likely to engage in long-term relationships compared to heterosexual men, but were significantly more likely to desire long-term relationships compared to heterosexual men and not more likely to desire hookups. Cultural scripts associated with hookups and casual sex among homosexual men (Klinkenberg \& Rose, 1994), in addition to norms shaping men's behavior more generally may therefore encourage more engagement in hookup encounters while precluding involvement in long-term relationships, despite student's actual interest in those types of relationships. Structural opportunities to meet partners may also contribute to this pattern; since homosexual men have a relatively small number of compatible matches on campus, they may have difficulty in finding 
long-term relationship partners. However, the fact that this pattern is present for homosexual men but not women, who face similar structural constraints, is more consistent with a cultural explanation for these patterns.

Table 5. Hypotheses and outcomes.

\begin{tabular}{|c|c|c|}
\hline Hypothesis & Reason & Outcome \\
\hline GI: HK desire: $M>W$ & Norms, Bio & $\mathrm{T}$ \\
\hline G2: HKs: $M>W$ & Norms, Bio & $\mathrm{T}$ \\
\hline G3: LTRs: W > M & Norms, Bio & $\mathrm{T}$ \\
\hline G4: DTs: W> M & Norms, Bio & $\mathrm{F}$ \\
\hline G5: LTR desire: $W>M$ & Norms, Bio & $\mathrm{F}$ \\
\hline G6: DT desire: $W>M$ & Norms, Bio & $\mathrm{F}$ \\
\hline $\begin{array}{l}\text { G7: DTs and LTRs: \% female negatively } \\
\text { associated }\end{array}$ & Norms, Bio, Structure & $\mathrm{F}$ \\
\hline G8: HKs: $\%$ female positively associated & Norms, Bio, Structure & $\mathrm{F}$ \\
\hline SOI: HKs Ho, $\mathrm{Bi} M>$ Het $M$ & Norms, Bio, Structure & $\mathrm{T}(\mathrm{Ho}), \mathrm{F}(\mathrm{Bi})$ \\
\hline SO2: HKs: $\mathrm{Ho}, \mathrm{Bi} W \leq$ Het $W$ & Norms, Bio, Structural & $\mathrm{T}$ \\
\hline SO3: LTRs: Ho W > Het W & Norms, Bio, Structure & $\mathrm{F}$ \\
\hline SO4: All partnering: $\mathrm{Bi}>\mathrm{Het}, \mathrm{Ho}$ & Structure & $\mathrm{F}$ \\
\hline SO5: All partnering desire: $\mathrm{Bi}<\mathrm{Het}$, Ho & Structure, Networks & $\mathrm{F}$ \\
\hline $\begin{array}{l}\text { RI: All partnering: White } \mathrm{W}>\mathrm{W} \text { of all } \\
\text { other races }\end{array}$ & Desirability & $\mathrm{T}$ (HKs), F (Dts, LTRs) \\
\hline $\begin{array}{l}\text { R2: All partnering: Asian students < } \\
\text { other races }\end{array}$ & Norms, Desirability (Asian M) & $\mathrm{T}$ \\
\hline $\begin{array}{l}\text { R3: HK desire: } W \text { of all other races < } \\
\text { White } W\end{array}$ & Desirability, Tokenism & $\mathrm{F}$ \\
\hline R4: All partnering: $M$ of color $\leq$ White $M$ & Desirability, Tokenism & $\mathrm{T}$ \\
\hline $\begin{array}{l}\text { Rell: HKs: More religious < less religious } \\
\quad<\text { least religious }\end{array}$ & Norms & $\mathrm{T}(\mathrm{W}), \mathrm{F}(\mathrm{M})$ \\
\hline $\begin{array}{l}\text { Rel2: LTRs: More attendance }=\text { less } \\
\text { attendance }\end{array}$ & Norms & $\mathrm{T}(\mathrm{W})$ \\
\hline $\begin{array}{l}\text { Rel3: LTRs: More attendance < less } \\
\text { attendance }\end{array}$ & Selection & $\mathrm{F}$ \\
\hline Rel4: DTs: Attenders > nonattenders & Norms, Networks & $\mathrm{T}(\mathrm{M}), \mathrm{F}(\mathrm{W})$ \\
\hline $\begin{array}{l}\text { Rel5: LTRs: More attendance > less } \\
\text { attendance }\end{array}$ & Norms, Networks & $\mathrm{F}$ \\
\hline $\begin{array}{l}\text { GRI: HKs: Greek members > } \\
\text { nonmembers }\end{array}$ & Norms & $\mathrm{T}$ \\
\hline $\begin{array}{l}\text { GR2: HKs: Living in Greek housing or } \\
\text { independently > dormitories > } \\
\text { parents }\end{array}$ & Desirability & $\mathrm{F}$ \\
\hline $\begin{array}{l}\text { GR3: HKs: Campuses with more frats/ } \\
\text { sororities > campuses with fewer }\end{array}$ & Norms, Networks & $\mathrm{F}$ \\
\hline $\begin{array}{l}\text { GR4: LTRs: Campuses more frats/ } \\
\text { sororities } \leq \text { campuses with fewer }\end{array}$ & Norms & $\mathrm{T}$ \\
\hline GR5: LTRs: Members $\leq$ nonmembers & Norms & $\mathrm{T}$ \\
\hline
\end{tabular}

Note. $\mathrm{T}=$ true; $\mathrm{F}=$ false; $\mathrm{LTR}=$ long-term relationship; $\mathrm{DT}=$ date; $\mathrm{HK}=$ hookup; $\mathrm{W}=$ women; $\mathrm{M}=$ men; $\mathrm{Ho}=$ homosexual; $\mathrm{Bi}=$ bisexual; Het = heterosexual. Bio-evolutionary theory: norms related to partnering behavior and/or education; stratified social desirability: structure refers to number of available partners of a desired type; theory of Tokenism: selection refers to types of students who may join that group, social networks.

In contrast with our expectations and with past findings indicating women are more likely than men to prefer dates over hookups (Bradshaw et al., 2010), we found that women were not more likely to engage in or desire opportunities for dates than men, and men had a small but 
significantly higher number of past dates and an equal likelihood of desiring dating opportunities. This may be because men desire long-term relationships at a higher rate than women and are trying to form them; for both men and women, desire for long-term relationship opportunities is associated with increased rates of dating. Dates may also operate similar to hookups on campus, with higher engagement among those students (men) more interested in casual encounters. Women also participated in long-term relationships at a higher rate, which may preclude other dating opportunities.

In addition to shaping partnering norms, culture also impacts patterns of social desirability, which can shape partnering participation. Black women were most likely to want opportunities to hookup and Asian men and women were more likely than other groups to want more opportunities to hookup and date, but these groups were least likely to have engaged in these activities; Hispanic and other race women are also less likely to have hooked up compared to White women. It seems women of color therefore do not avoid casual sex partnering as members of 'token' groups, which would constrain their desire for these types of relationships but rather are constrained by a lack of structural opportunities resulting from racial preferences among potential partners that favor Whiteness (Laumann et al., 2004). Asian men are also less likely than White men to form long-term relationships, more than twice as likely to never form relationships, more likely to desire hookup and dating opportunities, and were the only racial group that showed distinctive partnering patterns among men. This is likely in part driven by controlling images that desexualize Asian men (Chan, 2001; Espiritu, 2008; Shek, 2007). While we predicted a cultural emphasis on academic achievement among Asian Americans (Ngo \& Lee, 2007; Sue \& Okazaki, 1990; Warikoo \& Carter, 2009) would reduce desire for partnering in this group, we do not find this to be confirmed by our data. It may be that time spent on studying and academic pursuits preclude engagement in other social activities, thus restricting access to partnering opportunities and resulting in the patterns found. Partnering patterns of Asian Americans is one area that future research would be well served to explore, to further disentangle the causes of these patterns.

In addition to social desirability, culture also works to shape partnering norms, and therefore partnering behavior. Greek culture encourages short-term partnering but not long-term partnering; therefore, sorority and fraternity members are able to take advantage of their more dense social networks to engage in higher rates of short-term partnering but are not more likely to engage in long-term relationships, despite women in sororities being more likely than nonmembers to wish they had more long-term relationship opportunities on campus. In this case, culture is more salient than structural opportunities to meet potential long-term romantic partners, despite being embedded in networks highly tailored to facilitating ties with others and intimate partnering specifically.

Similarly, religious service attenders also have a strong social network to draw from when searching for potential partners, which explains why men who attend occasional religious services have a higher rate of hooking up, dating, and all partnering, compared to students who do not attend religious services, despite participating in a culture that often proscribes casual sex. Women do not have higher rates of hooking up or dating when they occasionally attend services, perhaps reflecting sexual double standards or less religious compliance among men. This may also reflect a woman's higher religious attendance, as demonstrated in Table 1, a gender 
imbalance that may yield more available partners for men who occasionally attend services. Among the most frequent religious service-attending men, norms discouraging casual sex result in rates of hooking up that are equal to nonattenders despite these stronger social networking opportunities and despite lower desire for hookups among these men. The most religious women were also most likely to have never engaged in intimate partnering in college. In addition to conforming to norms of sexual chastity, frequent service attenders may miss other social opportunities to meet a wider range of potential partners, or perhaps attend services more often because they are single.

This study has several limitations. First is the nature of sampling; the colleges and courses in which the survey was administered was not a probability, and therefore not a representative sample. Although we controlled for a number of campus features in our models, overall descriptive statistics cannot be assumed to accurately reflect national trends among college students and should not be taken as representative in the strictest sense. Second, we examined the behavior of students at various stages of their education, rather than completed partnering rates at the end of their education, and our data set disproportionately sampled freshman and sophomores. Since additional time in college gives students additional opportunities to engage in partnering (Kuperberg \& Padgett, 2015), these effects depress overall partnering rates found with these data.

Finally, student respondents are largely left to rely on their own definitions of a "hookup" rather than being presented with specific definitions generated by researchers, and it is possible that students' understanding of a hookup may systematically vary with demographic or other differences. However, the essential features of a hookup used by researchers across existing literature are that hookups involve sex behaviors ranging from kissing to intercourse and that encounter participants are not currently in a committed relationship (Lewis, Atkins, Blayney, Dent, \& Kaysen, 2013), and students' concepts of typical hookups tend to show high consistency, indicating that a shared meaning for "hooking up" exists (Holman \& Sillars, 2012; Paul \& Hayes, 2002). Allowing students to use their own conceptions of hookups may also be a strength of these data, as doing so allows for analyses of encounters that include a wider range of sexual behaviors beyond intercourse, more accurately reflecting the variety of emerging adults’ casual sex experiences (Paul et al., 2000).

Past research on hookups has mostly focused on what type of activity occurs during, or just prior to, the hookup, while limited research has explored selection into hookups and number of casual sex partners by personality, attitudes toward sexuality, other individualistic and psychological characteristics, demographic characteristics, and local campus factors such as sex ratios (Adkins et al., 2015; Kuperberg \& Padgett, 2015; Lyons et al., 2013; Owen et al., 2010; Paul et al., 2000; Uecker \& Regnerus, 2010). In this study, we add to this literature by arguing that differences in the extent and type of intimate partnering relationships that students engage in are influenced by a combination of cultural and perhaps evolutionary biological factors influencing desire for partnering and structural constraints - to some extent shaped by culture - that limit available partners. The influence of culture explains several patterns of selection into romantic and sexual partnering that cannot be explained by biological, psychological, and structural factors alone. A fully integrated approach to understand patterns of intimate partnering must therefore account for cultural norms and scripts that shape behavior. 


\section{Authors' note}

The authors wish to thank R. James Leister for his research assistance and Paula England for her helpful comments on this article. This article was presented at the 2013 Southern Sociological Society conference, Atlanta, Georgia.

\section{Funding}

The author(s) disclosed receipt of the following financial support for the research, authorship, and/or publication of this article: Funding for this article was provided by The University of North Carolina at Greensboro New Faculty Research Grant and New Faculty Summer Excellence Award Grant as administered by the Office of Research and Economic Development.

\section{References}

Adkins T., England P., Risman B. J., Ford J. (2015). Student bodies: Does the sex ratio matter for hooking up and having sex at college? Social Currents, 2, 144-162.

Alksnis C., Desmaris S., Wood E. (1996). Gender differences in scripts for different types of dates. Sex Roles, 34, 321-336.

Armstrong E. A., England P., Fogarty A. C. K. (2012). Accounting for women's orgasm and sexual enjoyment in college hookups and relationships. American Sociological Review, 77, 435-462.

Armstrong E. A., Hamilton L. T., Armstrong E. M., Seeley J. L. (2014). 'Good girls': Gender, social class, and slut discourse on campus. Social Psychology Quarterly, 77, 100-122.

Bailey J. M., Gaulin S., Agyei Y., Gladue B. A. (1994). Effects of gender and sexual orientation on evolutionarily relevant aspects of human mating psychology. Journal of Personality and Social Psychology, 66, 1081-1093.

Baumeister R. F., Vohs K. D. (2004). Sexual economics: Sex as a female resource for social exchange in heterosexual interactions. Personality and Social Psychology Review, 8, 339-363.

Bogle K. A. (2008). Hooking up: Sex, dating, and relationships on campus. New York: New York University Press.

Borenstein M., Hedges L. V., Higgins J. P. T., Rothstein H. R. (2009). Introduction to metaanalysis. West Sussex, England: John Wiley and Sons.

Bourdieu P., Johnson R. (1993). The field of cultural production: Essays on art and literature. New York, NY: Columbia University Press.

Bradshaw C., Kahn A. S., Saville B. K. (2010). To hookup or date: Which gender benefits? Sex Roles, 62, 661-669. 
Brimeyer T. M., Smith W. L. (2012). Religion, race, social class, and gender differences in dating and hooking up among college students. Sociological Spectrum, 32, 462-473.

Burdette A. M., Ellison C. G., Hill T. D., Glenn N. (2009). 'Hooking up’ at college; Does religion make a difference? Journal for the Scientific Study of Religion, 48, 535-551.

Bureau of Labor Statistics. (2014). College enrollment and employment of high school graduates in 2013. Retrieved January 10, 2015, from http://www.bls.gov/news.release/pdf/hsgec.pdf

Buss D. M., Schmitt D. P. (1993). Sexual strategies theory: An evolutionary perspective on human mating. Psychological Review, 100, 204-232.

Carroll J. S., Willoughby B., Badger S., Nelson L. J., Barry C. M., Madsen S. D. (2007). So close, yet so far away: The impact of varying marital horizons on emerging adulthood. Journal of Adolescent Research, 22, 219-247.

Chan J. (2001). Chinese American masculinities: From Fu Manchu to Bruce Lee. New York \& London: Taylor \& Francis.

Cohen J. (1988). Statistical power analysis for the behavioral sciences (2nd ed.). Hillsdale, NJ: Lawrence Erlbaum.

Collins P. H. (2002). Black feminist thought: Knowledge, consciousness, and the politics of empowerment. New York, NY: Routledge.

Confer J. C., Easton J. A., Fleischman D. S., Goetz C. D., Lewis D. M., Perilloux C., Buss D. M. (2010). Evolutionary psychology: Controversies, questions, prospects, and limitations. American Psychologist, 65, 110.

Coontz S. (2006). Marriage, a history: How love conquered marriage. New York, NY: Penguin.

Crissey S. R. (2005). Race/ethnic differences in the marital expectations of adolescents: The role of romantic relationships. Journal of Marriage and Family, 67, 697-709.

Dugger K. (1988). Social location and gender-role attitudes: A comparison of Black and White women. Gender \& Society, 2, 425-448.

Eisenberg M. (2001). Differences in sexual risk behavior between college students with samesex and opposite-sex experiences: Results from a national survey. Archives of Sexual Behavior, 30, 575-589.

Eisenberg M. E., Ackard D. M., Resnick M. D., Neumark-Sztainer D. (2009). Casual sex and psychological health among young adults: Is having "friends with benefits" emotionally damaging? Perspectives on Sexual and Reproductive Health, 41, 231-237. 
Ellis P. D. (2010). The essential guide to effect sizes: An introduction to statistical power, metaanalysis and the interpretation of research results. Cambridge, England: Cambridge University Press.

England P., Bearak J. (2014). The sexual double standard and gender differences in attitudes towards casual sex among U.S. university students. Demographic Research, 30, 1327-1338.

England P., Fitzgibbons Shafer F. E., Fogerty A. C. K. (2007). Hooking up and forming romantic relationships on today's college campuses. In Kimmel M. S. (Ed.), The gendered society reader (pp. 531-547). New York, NY: Oxford University Press.

Epstein M., Calzo J. P., Smiler A. P., Ward L. M. (2009). Anything from making out to having sex: Men's negotiations of hooking-up and friends with benefits scripts. Journal of Sex Research, 46, 414-424.

Espiritu Y. L. (2008). Asian American women and men: Labor, laws, and love, Second Edition. Lanham, MD: Rowman \& Littlefield Publishers.

Fine L. E. (2012). The context of creating space: Assessing the likelihood of college LGBT center presence. Journal of College Student Development, 53, 285-299.

Fontanella B. J. B., Gomes R. (2015). Sexual health care of two generations of men: Continuities and volatilities of scripts and habitus. Ciência \& Saúde Coletiva, 20, 259-272.

Foucault M. (1979). The history of sexuality. London, England: Allen Lane.

Fuller J. N., Frost A. M., Burr B. K. (2015). Exploring the impact of religiosity and socioeconomic factors on perceived ideal timing of marriage in young adults. Journal of Student Research, 4, 120-129.

Galperin A., Haselton M. G., Frederick D. A., Poore J., von Hippel W., Buss D. M., Gonzaga G. C. (2013). Sexual regret: Evidence for evolved sex differences. Archives of Sexual Behavior, 42, 1145-1161.

Gibbs J. P. (1965). Norms: The problem of definition and classification. American Journal of Sociology, 70, 586-594.

Grello C. M., Welsh D. P., Harper M. S. (2006). No strings attached: The nature of casual sex in college students. The Journal of Sex Research, 43, 255-267.

Hamilton L., Armstrong E. A. (2009). Gendered sexuality in young adulthood double binds and flawed options. Gender \& Society, 23, 589-616.

Harknett K., McLanahan S. S. (2004). Racial and ethnic differences in marriage after the birth of a child. American Sociological Review, 69, 790-811. 
Hasselblad V., Hedges L. V. (1995). Meta-analysis of screening and diagnostic tests. Psychological Bulletin, 1, 167-178.

Holman A., Sillars A. (2012). Talk about "hooking up”: The influence of college student social networks on nonrelationship sex. Health Communication, 27, 205-216.

Kanter R. M. (1977). Men and women of the corporation. New York, NY: Basic Books.

Kimmel M. (2008). Guyland: The perilous world where boys become men. New York, NY: Harper.

Klinkenberg D., Rose S. (1994). Dating scripts of gay men and lesbians. Journal of Homosexuality, 26, 23-35.

Kuperberg A., Padgett J. E. (2015). Dating and hooking up in college; Meeting contexts, sex, and variation by gender, partner's gender and class standing. Journal of Sex Research, 52, 517531.

Laumann E. O., Ellingson S., Mahay J., Paik A., Youm Y. (2004). The sexual organization of the city. Chicago, IL: University of Chicago Press.

Laumann E. O., Gagnon J. H., Michael R. T., Michaels S. (1994). The social organization of sexuality. Chicago, IL: University of Chicago Press.

Lehrer E. L., Chen Y. (2011). Women’s age at marriage and marital instability: Evidence from the 2006-008 National Survey of Family Growth. IZA discussion paper no. 5954. Retrieved November 1, 2011, SSRN from http://ssrn.com/abstract=1929654

Lewis M. A., Atkins D. C., Blayney J. A., Dent D. V., Kaysen D. L. (2013). What is hooking up? Examining definitions of hooking up in relation to behavior and normative perceptions. The Journal of Sex Research, 50, 757-766.

Lima C., Putnam R. D. (2010). Religion, social networks, and life satisfaction. American Sociological Review, 75, 914-933.

Lyons H., Manning W., Giordano P., Longmore M. (2013). Predictors of heterosexual casual sex among young adults. Archives of Sexual Behavior, 42, 585-593.

Massey D. S. (1981). Dimensions of the new immigration to the United States and the prospects for assimilation. Annual Review of Sociology, 7, 57-85.

McCartney K., Rosenthal R. (2000). Effect size, practical importance, and social policy for children. Child Development, 71, 173-180.

Nemoto K. (2006). Intimacy, desire, and the construction of self in relationships between Asian American women and White American men. Journal of Asian American Studies, 9, 27-54. 
Ngo B., Lee S. J. (2007). Complicating the image of model minority success: A review of Southeast Asian American education. Review of Educational Research, 77, 415-453.

Owen J. J., Rhoades G. K., Stanley S. M., Fincham F. D. (2010). 'Hooking up’ among college students: Demographic and psychosocial correlates. Archives of Sexual Behavior, 39, 653-663

Paul E. L., Hayes K. A. (2002). The casualties of 'casual' sex: A qualitative exploration of the phenomenology of college students' hookups. Journal of Social and Personal Relationships, 19, 639-661.

Paul E. L., McManus B., Hayes A. (2000 'Hookups’: Characteristics and correlates of college student's spontaneous and anonymous sexual experiences. Journal of Sex Research, 37, 76-88.

Plante R. F. (2006). Sexualities in context. Boulder, CO: Westview Press.

Rabe-Hesketh S., Skrondal A. (2008). Multilevel and longitudinal modeling using Stata. College Station, TX: Stata Press.

Raley R. K., Bratter J. (2004). Not even if you were the last person on earth! How marital search constraints affect the likelihood of marriage. Journal of Family Issues, 25, 167-181.

Regnerus M., Uecker J. (2011). Premarital sex in America. New York, NY: Oxford University Press.

Rose S., Frieze I. H. (1993). Young singles’ contemporary dating scripts. Sex Roles, 28, 499509.

Risman B. J., Davis G. (2013). From sex roles to gender structure. Current Sociology, 61, 733755.

Rosenfeld M. J. (2007). The age of independence: Interracial unions, same-sex unions, and the changing American family. Cambridge, MA: Harvard University Press.

Rupp L. J., Taylor V., Regev-Messalem S., Fogarty A., England P. (2014). Queer women in the hookup scene: Beyond the closet? Gender and Society, 28, 212-235.

Sanday P. R. (2007). Fraternity gang rape: Sex, brotherhood, and privilege on campus. New York, NY: NYU Press.

Shaffer J. P. (1995). Multiple hypothesis testing. Annual Review of Psychology, 46, 561-584.

Scott-Sheldon L. A., Carey K. B., Carey M. P. (2008). Health behavior and college students: Does Greek affiliation matter? Journal of Behavioral Medicine, 31, 61-70.

Shek Y. L. (2007). Asian American masculinity: A review of the literature. The Journal of Men's Studies, 14, 379-391. 
Simmel G. (1950). The sociology of Georg Simmel. New York, NY: Free Press.

Sipsma H. L., Ickovics J. R., Lin H., Kershaw T. S. (2015). The impact of future expectations on adolescent sexual risk behavior. Journal of Youth and Adolescence, 44, 170-183.

Sue S., Okazaki S. (1990). Asian-American educational achievements: A phenomenon in search of an explanation. American Psychologist, 45, 913-920.

Taylor K. (2013). Sex on campus: She can play that game, too. New York Times, Fashion and Style Section, July 12.

Uecker J. E., Regnerus M. D. (2010). Bare market: Campus sex ratios, romantic relationships, and sexual behavior. Sociological Quarterly, 51, 408-435.

Warikoo N., Carter P. (2009). Cultural explanations for racial and ethnic stratification in academic achievement: A call for a new and improved theory. Review of Educational Research, 79, 366-394. 